\title{
Inhibición de la $\beta$-oxidación de ácidos grasos como tratamiento en células tumorales tiroideas que expresan V600EBRAF
}

\author{
Sergio Díaz Gago a , Beatriz Gallego Tamayo, Antonio Chiloeches Gálvez \\ a.sergio.diazgago@edu.uah.es \\ IV Congreso de Señalización Celular, SECUAH 2019. \\ 20-22 de marzo, 2019. Universidad de Alcalá. Alcalá de Henares, Madrid. España. \\ Sesión A2, Cáncer.
}

Palabras clave: ATC; V600EBRAF; CPT1; Etomoxir; PLX4720

\section{Resumen}

El cáncer de tiroides es la patología más común del sistema endocrino y se estima que representa aproximadamente el $3 \%$ de los cánceres diagnosticados en EE.UU. El subtipo de cáncer de tiroides más agresivo es el carcinoma anaplásico tiroideo (ATC). Una mutación frecuentemente observada en los ATC es V600EBRAF, la cual provoca la activación constitutiva de la quinasa, favoreciendo la progresión tumoral. La inhibición de V600EBRAF provoca resistencias al tratamiento, por lo que son necesarias nuevas terapias para el tratamiento de tumores con esta mutación. Puesto que las células tumorales dependen en gran medida del metabolismo lipídico para satisfacer sus requerimientos proliferativos y energéticos, su modulación ofrece una buena opción para el desarrollo de terapias. En concreto, la inhibición de rutas metabólicas, como la oxidación de ácidos grasos tiene efectos antiproliferativos. Por ello nuestro objetivo es determinar la dependencia que tienen las células BHT101, derivadas de ATC y que expresan V600EBRAF, de la oxidación de ácidos grasos para su supervivencia, así como los cambios en las proteínas AMPK y mTORC1, dos reguladores maestros del metabolismo celular. Nuestros resultados demuestran que las células derivadas de carcinoma anaplásico tiroideo dependen de la oxidación de ácidos grasos para la supervivencia celular, debido a que el etomoxir, un inhibidor de la CPT1, provoca un descenso en la viabilidad, que se acompaña de la activación de AMPK y la inhibición de mTORC1. Además, observamos que la inhibición de la degradación de los ácidos grasos provoca un aumento en la producción de lactato, lo que sugiere que está aumentando el flujo glucolítico como compensación ante la pérdida de los ácidos grasos como sustrato energético. Por último, destacamos la terapia combinada de la inhibición de V600EBRAF y de la $\beta$-oxidación como una prometedora forma de tratamiento para los tumores que presentan dicha mutación, ya que el tratamiento combinado del PLX4720 con el etomoxir provoca un efecto antiproliferativo mayor tanto en viabilidad como en apoptosis y en la activación de AMPK, que dichos tratamientos por separado.

Cita: Díaz Gago, Sergio; Gallego Tamayo, Beatriz; Chiloeches Gálvez, Antonio (2019) Inhibición de la $\beta$ oxidación de ácidos grasos como tratamiento en células tumorales tiroideas que expresan V600EBRAF. Actas del IV Congreso de Señalización Celular, SECUAH 2019. 20-22 de marzo, 2019. Universidad de Alcalá. Alcalá de Henares, Madrid. España. Sesión A2, Cáncer. dianas 8 (1): e201903a23. ISSN 1886-8746 (electronic) journal.dianas.e201903a23 http://www3.uah.es/dianas?e201903a23. URI http://hdl.handle.net/10017/15181

Copyright: @ Díaz-Gago S, Gallego-Tamayo B, Chiloeches-Gálvez A. Algunos derechos reservados. Este es un artículo open-access distribuido bajo los términos de una licencia de Creative Commons ReconocimientoNoComercial-SinObraDerivada 4.0 Internacional. http://creativecommons.org/licenses/by-nc-nd/4.0/ 